PREHOSPITAL CARE

\title{
A hospital response to a soccer stadium stampede in Zimbabwe
}

\section{F D Madzimbamuto}

Correspondence to:

Dr F D Madzimbamuto,

Department of Anaesthesia and Critical Care

Medicine, University of

Zimbabwe Medical

School, Box A178,

Avondale, Harare,

Zimbabwe; faraitose@

hotmail.com

Accepted for publication 4 March 2003
Objectives: When a soccer stadium stampede occurred in Zimbabwe on 9 July 2000, the hospital disaster (medical emergency) plan failed. This report describes the use of the audit technique to change the hospital's disaster preparedness.

Method: A literature review was done to establish international standards of best practice in major medical incident response. The hospital disaster plan (major medical incident plan) was reviewed and used as local standard. Written submissions and unstructured interviews technique were used to collect information from staff present on the day and involved in the care of the stampede victims and from staff specified in the hospital disaster plan. This was presented as a report to the Hospital Clinical Audit and Quality Assurance Committee (CAQAC), with recommendations.

Results: The hospital's response to the disaster was suboptimal. The initial recommendations were accepted. Implementation is ongoing while discussion is drawing in other people and agencies. An integrated prehospital care system is required. The casualty department needs to develop into a modern accident and emergency department. Individual departments need to develop their own disaster plans that link into the hospital plan. A system for future audits of the hospital's performance after a disaster need to be put in place. Implementation of these recommendations is changing disaster preparedness in and out of the hospital.

Conclusions: The exercise was very useful in raising awareness and the value of audit and specific issues were defined for improvement. Long term and short term goals were set. Despite the shortage of resources, change was felt to be necessary and possible.
D uring 2001 there were four football stadium stampedes in Africa resulting in 180 deaths and unreported number of injured. This trauma to the families and communities of the victims is significant. Soccer fans going to watch games tend to be young, often wage earners or students whose loss or injury has an important economic impact on the family and country. Poor crowd control, use of CS tear gas, and poor response by the emergency services have been identified as aggravating factors. ${ }^{1}$ This generates considerable public anger, which is not resolved by the responsible agencies. Communities are confronted by the low value placed on human life by the authorities whose responsibility it is to protect public interest but feel powerless to make them accountable.

There are several areas to be considered regarding mass gatherings including the organisation of emergency health services. The medical profession in developing countries, in its quest to improve the health of their constituencies, has to show better leadership in tackling issues relating to mortality and morbidity in mass gatherings. The way in which casualties are managed reflects the way in which the health services are organised, the level of leadership and accountability within the health services, and the value placed on individual lives when these events happen. Described is how one hospital responded to a football stadium disaster by initiating an audit process.

On Sunday 9 July 2000, there was a World Cup soccer qualifying match between Zimbabwe and South Africa at the National Sports Stadium in Harare. At about 1640, eight minutes from the final whistle, South Africa scored to lead by two goals to nil. A plastic bottle was thrown onto the field hitting the goal scorer on the head, which halted the match. The police responded by using tear gas. In the ensuing stampede, 13 people died and many were injured.
Forty thousand people watched the game at the stadium with a capacity of 60000 . People watching the event on television did not realise the seriousness of the event. Informal discussion among hospital staff regarding response to the incident, showed that there was dissatisfaction with the hospital's response. The Clinical Audit and Quality Assurance Committee (CAQAC) of Parirenyatwa Hospital instituted an investigation. The aim was to determine the hospital's response in relation to its pre-existing disaster plan and to international standards in the practice and preparedness for mass casualty incident.

The remit of the committee was to improve the effectiveness of the hospital disaster plan, improve preparedness in the event of future and more serious medical emergencies, and to raise awareness of the audit processes as a method of bringing about change of practice.

\section{SETTING}

There are two main tertiary referral hospitals in Harare, Zimbabwe. Patients are referred to them mainly on a geographical basis. The national sports stadium is in the catchment area of the Parirenyatwa Hospital, a 1000 bed teaching hospital. All the major specialties are represented.

\section{METHODS OF AUDIT}

A team of three members (including the author) was tasked to carry out the audit. Literature was sought from the internet, library journals, and from other sources defining the international standards for management of mass casualty incidents. The medical school library did not stock any current leading journals in accident and emergency medicine, during the period of this investigation.

Information was sought by written submissions or unstructured interviews from everyone who was involved in 
Table 1 Notification of the incident

\begin{tabular}{|c|c|c|c|}
\hline Local standard & International standard ${ }^{2}$ & Local conditions & Local response \\
\hline $\begin{array}{l}\text { The hospital disaster plan } \\
\text { states }^{3} \text { : Police responsible } \\
\text { for notification. }\end{array}$ & $\begin{array}{l}\text { (a) Once notification confirmed, } \\
\text { a stand by team of emergency } \\
\text { doctors and nurses go to incident site. }\end{array}$ & $\begin{array}{l}\text { The stadium security department has the } \\
\text { responsibility of liaising with the police and } \\
\text { ambulance services. The city of Harare } \\
\text { Ambulance Service would normally be present } \\
\text { at all mass gatherings in the city. The stadium } \\
\text { is considered state property and therefore not } \\
\text { under the city's jurisdiction. On this occasion } \\
\text { they were not invited as would normally be } \\
\text { the case. } \\
\text { The city of Harare ambulance service provides } \\
\text { prehospital care through a doctor led team } \\
\text { and paramedic teams. The central hospitals do } \\
\text { not have a stand by emergency team to send } \\
\text { to any disaster. }\end{array}$ & $\begin{array}{l}\text { No arrangements had been } \\
\text { made to have the ambulance } \\
\text { services present at the stadium. } \\
\text { There was no notification by the } \\
\text { police. } \\
\text { - Spectators at the stadium called } \\
\text { the ambulance stations using } \\
\text { mobile phones. }\end{array}$ \\
\hline $\begin{array}{l}\text { Casualty senior staff verify } \\
\text { and inform switchboard: } \\
\text { triggering a cascading } \\
\text { process of notification. }\end{array}$ & $\begin{array}{l}\text { (b) The ambulance team and the } \\
\text { medical incident officer (MIO) to } \\
\text { coordinate and communicate with } \\
\text { receiving hospital about patients. }\end{array}$ & & $\begin{array}{l}\text { The casualty department first } \\
\text { became aware of the event when } \\
\text { the injured arrived and reported } \\
\text { "many injured at the } \\
\text { stadium"(personal } \\
\text { communication). }\end{array}$ \\
\hline
\end{tabular}

the care of the cases from the stadium incident or those whose role is specified in the disaster plan. Staff were asked whether they had been involved in this medical emergency response and what their experience and their overall assessment was of the performance of the hospital.

A report was presented to the Clinical Audit and Quality Assurance Committee (CAQAC) with recommendations for improving disaster preparedness. Implementation of the recommendations has involved all the departments and services in the hospital, the prehospital service providers in the City of Harare, the Ministry of Health and its national structures, and finally the local World Health Organisation office for disaster preparedness and management.

A disaster is defined as environmental damage, personal injury, or death on a scale that overwhelms the ability of available services to cope. Where human injuries predominate the term mass casualty incident is sometimes used. A disaster plan is a protocol for the management of a disaster. The protocol for the response of the medical services is referred to as the medical emergency plan.

\section{RESULTS}

The results are shown in tables 1,2 , and 3.

Good documentation is essential in a disaster in which medicolegal issues may arise either at the time or later. There was loss of information on some patients later found to have been stadium stampede victims, because the control centre was not functioning as such. Thirty nine patients were treated for minor injuries, four were admitted to intensive care beds, and 12 were certified dead in casualty. The 13th patient was certified dead on arrival Harare Central Hospital, the supporting hospital. Casualty, surgical, and anaesthetic staff treated the four ICU patients, who were admitted initially in the resuscitation room. Three patients were admitted to the adult ICU and one to the paediatric intensive care unit. Receiving teams in the casualty department are essential because when patients are passed from one person or team to another there is loss of information about that patient, with discontinuity of care that delays management. In addition experienced clinicians managing these patients can intervene early and anticipate clinical developments before they occur. Such teams stay with the patient up to the point of definitive care or hand over.

Inpatients would normally take priority over outpatients because they are sicker. A plain chest and cervical radiograph would normally be considered mandatory in all blunt trauma patients. No radiological or laboratory tests were done for 18 hours on these ICU patients although "walking wounded" were radiographed so they could be discharged home. Additional staff could not be brought in because of industrial

Table 2 In the casualty department

\begin{tabular}{|c|c|c|c|}
\hline Local standard & International standard ${ }^{45}$ & Local conditions & Local response \\
\hline \multirow[t]{2}{*}{ None stated } & $\begin{array}{l}\text { (a) A team consisting of a } \\
\text { surgeon, anaesthetist, and } \\
\text { nurse at each casualty bay for } \\
\text { receiving disaster victims. }\end{array}$ & $\begin{array}{l}\text { The casualty department } \\
\text { was overwhelmed by } \\
\text { injured arriving with family } \\
\text { and friends }\end{array}$ & $\begin{array}{l}\text { Most of the injured were } \\
\text { taken to hospital in } \\
\text { private cars so did not } \\
\text { receive on site triage. } \\
\text { Even with patients } \\
\text { carried by ambulance } \\
\text { there was no on site } \\
\text { triage to inform decision } \\
\text { making at the receiving } \\
\text { hospital. }\end{array}$ \\
\hline & $\begin{array}{l}\text { Triage started at the disaster } \\
\text { site to continue at the } \\
\text { receiving hospital. }\end{array}$ & $\begin{array}{l}\text { Staff reinforcements could } \\
\text { not be contacted because of } \\
\text { out of date hospital telephone } \\
\text { systems }\end{array}$ & $\begin{array}{l}\text { Hospital staff who were } \\
\text { not on duty were not } \\
\text { called. } \\
\text { No teams were set up to } \\
\text { manage patients in } \\
\text { casualty particularly the } \\
\text { critically injured ones. }\end{array}$ \\
\hline
\end{tabular}


Table 3 The care in the hospital

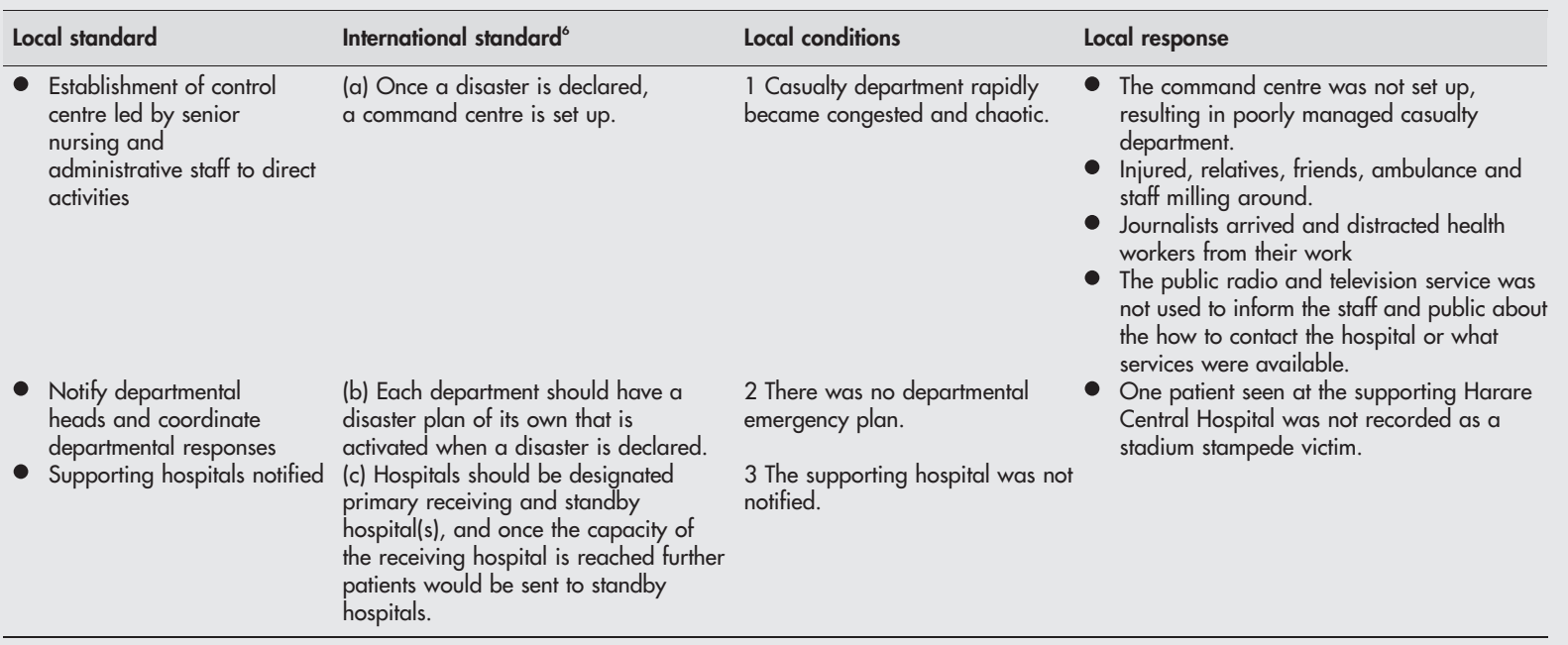

action at the time, making the service more erratic and unreliable. In addition no psychological referral was made during the hospital stay. The psychological trauma of such events on staff, relatives, and victims can be very severe, ${ }^{7}$ but the support services were not available. The identification of deceased victims and necropsy services should be under the direction of a forensic pathologist. ${ }^{8}$ No staff debriefing took place after the event as suggested by the literature.9 ${ }^{10}$

\section{THE REVIEW}

After the initial presentation of the report to the hospital's CAQAC, the recommendations were widely publicised within the hospital services and other organisations. Follow up meetings were held with wider sections of people involved in disaster preparedness and management. The aim was to review again the facts of what had transpired on the 9 July, disseminate the principles of best practice, and focus on areas of improvement. Participants included healthcare leaders from other parts of the country and representatives of organisations involved in acute care of mass casualties.

The recommendation that the prehospital emergency medical service should be integrated with the hospitals was widely accepted. One of the measures is to site a telephone hotline in the casualty department to the ambulance switchboard. The need to develop the casualty department into an accident and emergency service with appropriately trained leadership, was emphasised. ${ }^{11}$ Despite the scarcity of resources, this was viewed as the only way to face the challenges for the future.

All the individual departments and services were to review the hospital disaster plan, find ways of improving their participation and implementation, and develop their own departmental medical emergency plan.

Since then, the Ministry of Health has started a nationwide campaign in disaster preparedness and management involving health and non-health sector services. A task force has been set up to keep the momentum going and develop simple methods of monitoring preparedness. Re-organisation of the casualty department is underway but more resources will be required in the restructured department. Departmental disaster plans are being reviewed now with a proposal to introduce action cards with a department specific bullet point summery of the disaster plan on one side and key points from the general plan on the reverse side. In addition several forces are converging to develop a portable trauma course to heighten awareness of the management of trauma victims.
Table 4 Stadium diasters in Africa in the past 10 years

\begin{tabular}{llll}
\hline Year & Country & Injured & Died \\
\hline 2001 & Ghana & $?$ & 126 \\
2001 & South Africa & 160 & 43 \\
2001 & Ivory Coast & $?$ & 1 \\
2001 & DR Congo & 51 & 10 \\
2000 & Zimbabwe & 45 & 13 \\
1999 & Egypt & $?$ & 11 \\
1998 & DR Congo & $?$ & 4 \\
1998 & Zambia & $?$ & 8 \\
1997 & Zimbabwe & $?$ & 5 \\
1996 & Nigeria & $?$ & 5 \\
1996 & Zambia & $?$ & $?$ \\
1995 & Sierra Leone & $?$ & $?$ \\
1991 & Kenya & $?$ & $?$ \\
1991 & South Africa & $?$ & $?$ \\
\hline
\end{tabular}

Over the past 10 years there have been 14 stadium stampedes reported in Africa. The numbers of injured and killed are not well recorded. The response of the medical services is even less reported. (Figures compiled from newspaper reports suggest about four to five times as many are injured as killed).

The newly formed National Clinical Audit and Quality Assurance Foundation is using the hospital's experience as a model for using clinical audit as a tool for quality improvement in health delivery nationally.

Poor organisation and unpreparedness were recognised as having the potential to increase to a higher level the grading of a mass casualty incident. Further activities are planned in the future to improve the immediate care of trauma victims.

\section{DISCUSSION}

There is a growing body of literature regarding incidents associated with mass gathering events and preparedness. ${ }^{10}{ }^{12-15} \mathrm{~A}$ mass casualty incident has the typical features of a smaller number of severe, even fatal, injuries, and a wider circle of increasing numbers but of diminishing severity. They are unpredictable but can be anticipated. Preparedness and preventive measures are the hallmark of effective medical management.

It is clear that the stadium mass casualty incident was a disaster for the hospital and the city of Harare disaster plan. There was no preparedness by all the participants. No part of it was implemented effectively despite drills having been done in the past to test the plan. In addition the hospital disaster plan falls short of current international standards of 
practice. Clearly the lack of proper prehospital care played a significant part in the mortality. The hospitals generally should be part of a general prehospital plan in whatever area they find themselves. ${ }^{16}{ }^{17}$ In other countries the hospital has a liaison person who is in touch with the paramedical and other services outside the hospital, for example, police, fire brigade, etc. Prior to any mass gathering within the catchment area of the hospital, a medical incident preparedness plan is activated.

Most reports in the literature of mass casualty incidents are of resource rich countries. ${ }^{18-20}$ There is functioning infrastructure and resources can be made available. The public expects full inquiries into the events leading up to and management of disasters. Their mass casualty events are well recorded and reported. In the developing world mass casualties are not uncommon. The recording and reporting is poor and consequently the factors learned are forgotten. That means we do not learn from our experiences. This may be because of a sense of helplessness in the face of insensitive and inflexible administrative and economic regimens. The stadium disaster in Zimbabwe is only one of several that have occurred in Africa over the past 10 years. (table 4). The pattern described here has been very similar in all. This report will add to the literature from the developing countries, which suggest practical interventions within our resources.

In news reports emphasis is often on the deaths, which have an immediate and striking emotional impact. However, the injured have longer term social and financial burden, which could be just as devastating and difficult to manage in poorer countries. It is estimated that there are four to five times more injured than killed in football stadiums in Africa.

Organisational failure is one of the key aspects leading to mismanagement of this disaster. It led to key decisions not being taken, resources not being available or inappropriately used, poor patient outcome, and low staff morale.

In future it will not be possible to plead insufficient funding, low litigation rate, and a generally accepting population. The victims or their relatives were awarded compensation by FIFA (the International Federation of Football Associations) and ZIFA (Zimbabwe Football Association). The culture of seeking compensation has arrived, even in Zimbabwe. There is a class action against the police outstanding in relation to both deaths and injuries. Some of the survivors and relatives have continuing psychological, social, financial, and physical sequelae from which they have given notice to sue the responsible authorities.

In conclusion, the football disaster that occurred in Zimbabwe in the year 2000 has the characteristic features of a mass casualty incident. It was not managed appropriately. Several other football disasters have occurred in Africa in countries that have similar economic, political, and demographic features as Zimbabwe. The experiences can be assumed to be similar. This report will contribute to the literature and debate on how to manage mass casualty incidents in poorly resourced countries.
The hospital, acutely aware of the errors that took place on that day, is attempting to change its practice. The hospital Audit and Quality Management Committee has been key in highlighting the issues throughout the institution and nationally. In doing so, staff awareness and patient care and safety are improved. Factors outside the hospital are beyond its control but the responsible authorities have been engaged and dialogue started.

\section{ACKNOWLEDGEMENTS}

Acknowledgements are due to Dr C S Ray, Public Health Specialist, SAfAIDS, Harare, Zimbabwe, for assistance with the drafts and final revision. Mr A Dube, at the time Chairman of the Hospital Clinical Audit and Quality Assurance Committee and now Chair of the National Clinical Audit and Quality Assurance Foundation. He supported the work throughout and obtained permission from the Ministry of Health to publish the work. Professor Jonsson, Department of Surgery in the University of Zimbabwe Medical School for his support and comments on the several drafts. Dr Peter Oakley, North Staffordshire Medical Centre, Stoke on Trent, Staffordshire. UK for his critical comments on the initial hospital report. A paper based on this work was presented at the 2nd All Africa Anaesthesia Congress 22-26 September in Durban, South Africa. An abstract appears in the congress documents.

\section{REFERENCES}

1 Mutungamiri L. Parade Magazine 2000;September:15-18.

2 Miles S. Major accidents: $A B C$ of major trauma. BMJ 1990;301:919-23.

3 Parirenyatwa Group of Hospitals. Action plan for disaster management. Harare: Parirenyatwa Group of Hospitals, Aug 1995.

4 Karabasi A. Hospital disaster planning. 2nd European Congress of Trauma and Emergency Surgery. Athens, Greece. 1-4 Oct 1997.

5 Anony mous. This time it was not a drill. (Personal view) BMJ 1999;319:1079.

6 Phuli Lewis C, Aghababian RV. Disaster planning, part I: overview of the hospital and emergency department planning for internal and external disaster. Emerg Med Clin North Am 1996;14:439-52.

7 Hollander D. Nairobi bomb blast-trauma and recovery. Trop Doct 2000;30:47-8.

8 Busuttil A, Jones JSP, Green MA. Deaths in major disasters - the pathologists role. 2nd edn. London: Royal College of Pathologists, 2000.

9 Carlay S, MacKway Jones K. Are British hospitals ready for the next major incident? Analysis of hospital major incident lans. BMJ 1996;313:1242-3.

10 Williams KN, Squires S. Experience of a major incident alert at two hospitals: "the Soho bomb". Br J Anaesth 2000;85:322-4.

11 Sakr M, Wardrope J. Casualty, accident and emergency or emergency medicine, the evolution. J Accid Emerg Med 2000;17:314-19.

12 Meehan P, Toomey KE, Drinnon J, et al. Public health response for the 1996 Olympic Games. JAMA 1998;279:1469-73.

13 Green GB, Burnham G. Health at mass gatherings. JAMA 1998;279:1485-6.

14 Shelton S, Haire S, Gerard B. Medical care for mass gatherings at collegiate football games. S Med J 1997;90:1981-3.

15 Hodgetts TJ, Cooke MW. The largest mass gathering-medical cover for the millennium celebration needs careful planning. BMJ 1999;318:957-8.

16 Johnson DEA. Emergency medical services integration into hospital disaster planning. Topics in Emergency Medicine 1998;20:1-7.

17 Veronesi J, Kampare E. Mass casualty incidents: from field to inpatient care. Topics in Emergency Medicine 1998;20:8-14.

18 Wilkinson S. Port Arthur disaster. Aust N Z J Surg 1999;69:569-70.

19 Hogarth WD, Neil GF. Anatomy of a disaster: one hospitals experience and recommendations. Canadian Journal of Emergency Medicine 2001 ; 3:38-40.

20 Sookram S, Borkent H, Powell G, et al. Tornado at Pine Lake, Alberta-July 14, 2000. Assessment of the emergency medicine response to a disaster. Canadian Journal of Emergency Medicine 2001;3:34-7. 